\section{A recategorização como processo de construção de objetos de discursos: quando grafitar é transformar a realidade}

Francisca Poliane Lima de OLIVEIRA (UECE) meuemail.poly@gmail.com

Maria Helenice Araújo COSTA (UECE) mariahelenicearaujo@gmail.com

Recebido em: 18 de jan. de 2018. Aceito em: 07 de jun. de 2018.
OLIVEIRA, Francisca Poliane Lima de; COSTA, Maria Helenice Araújo. A recategorização como processo de construção de objetos de discursos: quando grafitar é transformar a realidade. Entrepalavras, Fortaleza, v. 8, p. 137-155, n. 2, maio/ago. 2018.

Resumo: Pelos relatos que temos sobre a escrita, no decorrer da história, constatamos que o graffiti convive conosco há muito tempo. Atualmente, estas marcas "expressam com traços, letras e desenhos, as contradições implicadas na vivência urbana contemporânea". A partir dessa premissa nos dedicamos a analisar uma obra que nos chamou a atenção por sua peculiaridade em termos de produção. Para tanto, nos apropriamos de uma concepcão dinâmica de texto - em que este é tido como um evento comunicativo (BEAUGRANDE, 1997) - e também de uma noção de recategorização que aponta para além da materialidade textual (COSTA, 2007; JAGUARIBE, 2007). Além das observações acerca do fazer nesta obra específica, buscamos ainda mostrar o poder de transformação social, cognitiva e estética que os graffitis podem operar na realidade. Estudar mais detidamente uma situação de produção textual, como essa que trouxemos aqui, nos fez ver como se processa a discretização do mundo nos discursos e como se dá a junção da vida com a arte. Tomar o exemplar desta análise do modo como o fizemos nos auxiliou a pensar atentamente acerca dessa característica de dinamismo das produções de linguagem sobre a qual viemos falando e ainda a mostrar que a recategorização é um processo que ocorre também em nível extratextual, ou seja, sobre a realidade.

Palavras-chave: Recategorização. Graffitis. Texto. 
v. $8(2)$

$137-155$

mai/ago 2018

Abstract: Through the reports we have on writing, throughout history, graffiti has been living with us for a long time. Today, these brands "express with traces, letters and drawings, the contradictions implied in the contemporary urban experience". From this premise we are dedicated to analyzing a work that has caught our attention because of its peculiarity in terms of production. In order to do so, we adopt a dynamic conception of text - in which it is seen as a communicative event (BEAUGRANDE, 1997) - and also of a notion of recategorization that points beyond textual materiality (COSTA, 2007; JAGUARIBBE, 2007). In addition to the observations about doing in this specific work, we also seek to show the power of social transformation, cognitive and aesthetic that graffiti can operate in reality. To study more closely a situation of textual production like the one we brought here, made us see how the discretization of the world in the speeches takes place and how the union of life with art takes place. Taking the example of this analysis as we have done here has helped us to think carefully about this characteristic of dynamism of the language productions about which we have been speaking and still to show that recategorization is a process that also occurs at an extratextual level, about reality.

Keywords: Recategorization. Graffiti. Text.

\section{Introdução}

Às vezes, considerada por pessoas mais conservadoras como ato de vandalismo, a arte do graffiti ${ }^{1}$ - de acordo com grafiteiros como Emol $^{2}$ (2014) - não tem necessariamente uma relação com poluição, sujeira ou agressão. Pelos relatos que temos sobre a escrita, no decorrer da história, é possível percebermos que essa manifestação convive conosco há muito tempo, como nos aponta Rink (2013, p. 19):

[...] na história humana, há mostras de que a intervenção pictórica e gráfica nos espaços urbanos existiu desde os primórdios da civilização revelando-se produtora de cultura em diversas sociedades.

Se observarmos o mundo a nossa volta, poderemos perceber que o que antes eram "marcas feitas com ponta de carvão nas paredes, rochas ou outras superfícies" tornaram-se maneiras bastante peculiares de comunicação. Atualmente, estas marcas parecem apresentar-se "como uma forma de manifestação urbana que expressa com traços, letras e desenhos, as contradições implicadas na vivência urbana contemporânea", como nos faz entender Orlandi (2004 apud FURTADO, 2007, p. 13). A este novo fazer nomeamos de graffiti.

Se pensarmos no graffiti apenas enquanto imagem - se é que podemos - observaremos uma mudança estética e também

\footnotetext{
${ }^{1}$ Nesta exposição, para nos referir a essa atividade criativa, usaremos o termo graffiti - originado do italiano, significando "escritas feitas com carvão" - e não à sua forma portuguesa, grafite, que poderia nos remeter à mina de lápis.

${ }^{2}$ Reflexões extraídas de notas de aula por ocasião do curso graffiti como escrita de rua.
} 
comportamental. Evoluindo da assinatura (tag) para produções mais complexas, arriscamos afirmar que essa transformação pela qual passou o graffiti esteja seguindo o fluxo natural de qualquer produção artística. A esse respeito, Amarante (2012, p. 54), ao refletir acerca das mudanças que incidiram sobre a imagem na passagem dos anos, explica que "o estatuto da imagem se alterou ao longo dos milênios e séculos, passando por temas ritualísticos primitivos, ornamentais, religiosos, ideológicos, políticos e, claro, artísticos [...]". Desta forma, entenderemos que as cidades e a sociedade não apenas sofreram modificações, mas aquilo que nelas e delas vive também se atualizou.

Ante a realidade plural que ora presenciamos, podemos dizer que todos os estatutos da imagem mencionados anteriormente coexistem e o graffiti, como parte de tal multimodalidade, perpassa todos esses matizes, mas não somente como semiose imagética; podemos - e devemos - percebê-lo enquanto linguagem³ ${ }^{3}$. Nesse sentido, o artigo que ora apresentamos propõe que o graffiti seja considerado para além da materialidade visual e que possa ser percebido como evento comunicativo.

Para melhor nos situarmos nessa proposta, a concepção de texto de Beaugrand (1997) e as ideias de Hanks (2008) sobre texto e textualidade, bem como o conceito de recategorização - atualizado em Oliveira (2012) - nos auxiliarão nas reflexões de como se processa a transformação da realidade em objetos de discurso em um graffiti feito na cidade de Londres.

Ao estruturar a apresentação dessas ideias, começamos por discutir a concepção de texto e de recategorização, criando um espaço teórico específico onde ancoraremos, com as explanações sobre a relação da sociedade com os graffitis, a análise do exemplo selecionado.

Quanto à escolha do material analisado, esta se deu em função do que podemos chamar de "presença de espírito do grafiteiro", que, ao ter seu graffiti apagado, transformou o funcionário encarregado dessa tarefa num novo graffiti, atualizando seu projeto de dizer. Nessa perspectiva, foi inevitável não percebermos a relação da realidade com o fazer do material em apreço e os efeitos de sentido produzidos a partir dessa interação.

Nas considerações finais, tecemos algumas reflexões em linhas mais gerais a respeito de nosso percurso, ao mesmo tempo em que sugerimos que esse tipo de produção textual e artística seja visto em todo seu potencial comunicativo e não apenas como parte da paisagem urbana.

${ }_{3}^{3}$ Manifestação de comunicação que engloba as noções de semiose verbal, não-verbal e para-verbal na formulação dos enunciados. 
v. $8(2)$

$137-155$

mai/ago 2018

\section{Conceituando texto dentro do panorama de criação colaborativa dos sentidos e da realidade}

Para melhor dizer sobre nossa atuação nesta análise, é preciso antes fazermos algumas considerações sobre a matéria que dá sustentação às reflexões que apresentaremos a partir daqui. Começamos por tentar delinear a noção de texto, não apenas por ser prática comum nas pesquisas que se fazem em linguística - principalmente a textual -, mas porque entendemos ser necessário estabelecermos o terreno dessas reflexões, para que seja possível visualizar sob que aspecto desenvolveremos as discussões apresentadas nesta pesquisa.

Ao longo de sua história, a Linguística Textual vem ampliando a noção de texto para adaptá-la aos novos graus de abrangência e de complexidade que vão sendo (re)incorporados aos estudos da linguagem pelo desenvolvimento das teorias da enunciação e do discurso. Se olharmos para trás, vamos encontrar visões mais estreitas e mais objetivistas, que reduzem o texto à materialidade verbal ou até mesmo a um tipo de artefato menos restrito, que chega a incluir o imagético.

Assim, com o desenvolvimento dos estudos no campo da Linguística Textual, vimos a noção de texto migrar da ideia de ser um produto - com um leitor assumindo um papel passivo - para uma visão que põe o texto como o "lugar da interação" (KOCH, 2006, p. 17) - com um sujeito ativo. Essa evolução representou mais do que um passo rumo à perspectiva social, deu ao texto um caráter dialógico, em que produtor e leitor participam conjuntamente no projeto de construção do(s) sentido(s).

Segundo Hanks (2008, p. 82), as abordagens do texto "inevitavelmente se fundam em algum conjunto de unidades ou níveis de organização textual, quer elas o façam explicitamente quer o façam por meio de assunções não explicitadas". Em nosso caso, nos aproximamos de uma posição na qual "a dimensão do poder no e do texto é de primordial importância, já que ela liga a formação textual com as relações sociais e um sistema cultural mais abrangente" (HANKS, 2008, p. 82).

Na perspectiva em que o texto é visto como fenômeno social de linguagem, ele pode ser entendido como a parte vital das relações de comunicação que se estabelecem ao longo de uma existência, já que "lidamos [com ele] cotidianamente em nossas práticas comunicativas" (BENTES, 2008, p. 19). Talvez por esse fato, muitos campos de pesquisa tenham se dedicado a estudá-lo e, em razão disso, tenham tentado defini-lo. 
Mas não basta definir, uma vez que, em acordo ao que Santaella (2003, p. 1) apresenta, definição é "uma espécie de morte, porque, sendo fechada, mata justo a inquietação e a curiosidade que nos impulsionam para as coisas que, vivas, palpitam e pulsam" e este posicionamento não se adéqua ao estatuto dinâmico de comunicação que objetivamos apresentar aqui.

Nosso intento com este trabalho inicial e reflexivo sobre o conceito de texto é organizar um arcabouço de ideias sobre as quais possamos assentar a noção necessária para mostrar - com base em nossas observações sobre o fazer do graffiti - que texto é, socioculturalmente, um produto e um processo. Ainda cremos ser possível defender que, dentro desta concepção, os graffitis - sendo um produto textual-cultural - são potencializadores de sentidos e transformadores da realidade.

Uma observação de Santaella (2003, p. 2) a propósito dos fenômenos de cultura e sua constituição como linguagem pode nos ajudar a reforçar o caráter sociológico de texto e a importância que tem considerar o graffiti do modo como abordaremos aqui.

Todo fenômeno de cultura só funciona culturalmente porque é também um fenômeno de comunicação e considerando que esses fenômenos só comunicam porque se estruturam como linguagem, pode-se concluir que todo e qualquer fato cultural, toda e qualquer atividade ou prática social constitui-se (sic) como práticas significantes, isto é, práticas de produção de linguagem e sentido (SANTAELLA, 2003, p. 2).

A partir desse prisma, o texto - a produção dos grafiteiros pode ser entendido como um construto complexo que dispõe de recursos de retomada, antecipação ou reelaboração da informação e do real. Podemos acrescentar, reiterando o que dissemos até agora, que essas colocações nos permitem ainda vê-lo como uma prática colaborativa.

Sendo assim, a concepção de texto proposta por Beaugrande (1997, p. 10) em que ele afirma que "é essencial ver o texto como um evento comunicativo no qual convergem ações linguísticas, cognitivas e sociais, não apenas como sequência de palavras ditas ou escritas", auxilianos na discussão que ora trazemos a propósito da produção textual do graffiti e a recriação da realidade operada por meio da interação com esta esfera de linguagem. Para o autor, o texto, como realidade emergente na

${ }_{4}^{4}$ It is essential to view the text as a communicative event wherein linguistic, cognitive, and social actions converge, and not just as the sequence of words that were uttered or written. 
v. $8(2)$

$137-155$

mai/ago 2018

interação, é multissistêmico, isto é, compõe-se de uma série de conexões entre elementos díspares; sons, palavras, significados, os sujeitos da interação, as ações em um determinado contexto etc.

Considerando as unidades que compõem a materialidade textual, podemos entender que elas são, assim, multifuncionais. Uma palavra, por exemplo, pode ser vista de diversas perspectivas: como uma sequência fônica, como elemento de uma estrutura sintática, como uma instrução para ativar um significado etc. Guardadas as devidas especificidades de cada modalidade, algo similar poderia ser dito em relação a outros tipos de elementos semióticos como a imagem e o som. O que deve ficar claro é que, ainda considerando as observações de Beaugrande (1997), não é apenas o artefato material que constitui o texto. Podemos dizer que esse artefato é apenas uma parte perceptível do texto enquanto processo semiótico que se configura e se reconfigura na interação.

O que dissemos anteriormente colabora para o entendimento do texto como processo dinâmico que ora defendemos e se junta ao que Hanks (2008, p. 84) afirma sobre construção de sentido, visto pelo ângulo da relação produto-processo-externalidade, "embora a conectividade formal e funcional possa fornecer uma base para o significado de um texto, é somente em união com o mundo sociocultural externo que ele se torna completo". Essa colaboração nos auxilia na construção de uma compreensão desse artefato em relação constante com elementos que estão no interior do processo de construção e fora dele.

Partindo do pressuposto de que, "mesmo que algum fragmento de texto possa ser interpretado de múltiplas formas [...] a gama de possibilidades nunca é infinitamente aberta no mundo social real" (HANKS, 2008, p. 88), vemos a necessidade de tocar nessa questão, já que entendemos que a produção dos textos está amparada em algum correlato no mundo e é interpretada também sob uma relação possível do leitor com o mundo, ou seja, linguagem e contexto enatuam na elaboração dos vários enunciados e das múltiplas significações.

Em oposição às teorias que entendem o contexto como algo localizado e efêmero, tomamos posição ao lado dos que o compreendem como um fenômeno contingencial, considerando com Hanks (2008) que os enquadres acontecem nas dimensões da emergência e da incorporação, ou seja, tais enquadres não são nem fundamentalmente mentais, nem unicamente centrados sobre o processo emergente de fala (HANKS, 2008).

$\mathrm{Na}$ esteira desse posicionamento, apresentamos a seguir o conceito de recategorização com o qual trabalhamos em nossas análises. 


\section{A recategorização na produção (inter)subjetiva de objetos de discurso no universo dos graffitis}

O conceito de recategorização defendido por Aphotéloz e Reichler Beguélin (1995) explica esse fenômeno como sendo a retomada de algo dito anteriormente na materialidade textual sob outro rótulo. Diversos autores como Koch (2004; 2006); Zavam (2007) e Leite (2007), por exemplo, seguiram essa linha de raciocínio e continuaram defendendo que a recategorização seria o processo de retomar de forma atenuada ou melhorada um referente existente no próprio corpo do texto.

Ao observar os pressupostos sociocognitivos da referenciação e a ação dialógica entre mente e mundo na constituição da linguagem e do próprio mundo, Ciulla e Silva (2008) atentou para a distinção que fazia entre os conceitos de categorização e recategorização em trabalhos anteriores e percebeu que a recategorização seria um processo mais dinâmico e que não se restringia, exclusivamente, a uma menção anterior no texto.

Em nossa pesquisa de mestrado (OLIVEIRA, 2012), percebemos, também, a recategorização ocorrendo para além da materialidade textual e, assim como Lima (2003), Jaguaribe (2007) e Ciulla e Silva (2008), passamos a defender um estatuto dinâmico e extramaterial para esse processo.

Desse modo, para nós, a recategorização é um processo que não se restringe à atualização de conceitos, mas principalmente à construção e reconstrução de realidades discursivas ou objetivas. Em outras palavras, ao produzirmos um enunciado, conforme Maturana (2001) explica, estamos reagindo a uma perturbação, ou seja, há algo exterior ao discurso e anterior à produção discursiva que desencadeia o que é produzido. Tal lógica nos remete ao que propôs Costa (2007) quando afirmou não haver grau zero de inferência na construção dos sentidos e nos leva a defender que a recategorização não depende de menção material anterior para ocorrer, esse processo é desencadeado a partir de nossa relação social, cognitiva e dialógica com o mundo.

Além disso, se tomarmos como base as considerações de Beaugrande (1997) sobre a constituição do texto, entenderemos a textualização (o ato de pôr o texto em movimento) como um processo de emergência de sentidos que ocorre nas negociações entre sujeitos da interação e se ligarmos tal pensamento ao que Mondada e Dubois (2003) chamam de fabricação de referentes ou objetos de discurso, podemos ainda entender que a recategorização - como parte constituinte da referenciação - constitui um dos importantes mecanismos geradores desse evento. 
v. $8(2)$

$137-155$

mai/ago 2018

Sendo assim, ao atentarmos para as ações que desenvolvemos com vistas à intercompreensão, perceberemos que parte do nosso esforço durante esse processo é dirigido para a busca de objetivação do nosso processo de dizer, ou seja, quando pomos o texto em movimento, estamos sempre construindo, retomando e reconstruindo nossos projetos de dizer. Para tanto, buscamos a palavra mais "adequada", usamos os gestos mais "eficientes", recorremos às imagens mais sugestivas das ideias que tentamos reificar. Nessa "luta" para dizer o que pretendemos, criamos e recriamos entidades discursivas, isto é, categorizamos e recategorizamos a realidade.

Ao observarmos esse fenômeno no processo criativo do design, percebemos que esse ato não se restringe apenas à materialidade textual nem somente a um dos lados da comunicação. Ao analisar a produção de peças de divulgação, vimos que a recategorização acontece na produção e na recepção do material produzido. Do lado do criativo, notamos esse fenômeno quando - em seu trabalho de elaboração - toma um elemento (não, necessariamente, da materialidade textual) e o retoma em seguida de forma ampliada, atenuada ou melhorada visando a fortalecer seu projeto de dizer; do lado do leitor percebemos o mesmo fenômeno, quando este participa com a responsabilidade de identificar e reavaliar o já dito ou o sugerido pelo falante.

Através dessas reflexões, pudemos concluir que, nesse processo de interação, a produção de sentidos funciona muito mais parecida com um trabalho coletivo do que com o acatamento de "ordens", principalmente quando temos em vista a fluidez dos discursos. Nesse sentido, não podemos deixar de lado o que se lê em Jaguaribe (2007, p. 232), que, ao considerar a recategorização como fenômeno sociocognitivo, deixa claro que essa atividade é um processo "que se resolve aquém e além da superfície textual".

Partindo dessas ideias, acreditamos que o processo recategorizador, no contexto de produção de graffitis, ocorre de maneira semelhante ao que acontece no design, isto é, em ambos os lados tanto no de quem produz, quanto no de quem lê. Além disso, o graffiti ainda promove uma reconstrução do próprio real, na medida em que se constitui como proposta de intervenção urbana, que adentra os espaços sociais construindo suas mensagens, promovendo reflexão e renovação das paisagens a partir da proposta de construção de sentidos.

A seguir continuamos a descrever a presença e a constituição do graffiti como meio de prosseguirmos nas análises da amostra escolhida para o presente estudo. 


\section{O graffiti no cotidiano das cidades}

A vida numa grande cidade é movida pelos horários estipulados e, muitas vezes, fica resumida aos caminhos a serem percorridos no cumprimento desses tais horários. Essa dinâmica nos faz ignorar um dado importante no cotidiano: a nossa relação com a vida, que passa pela interação com os demais e com a paisagem também.

Sabemos que o que mais conta nas cidades hoje é o fato de que elas influenciam, por meio de equipamentos materiais e imateriais, todos os aspectos da existência humana na vida capital, sendo fundamental para sua produção e reprodução (RINK, 2013, p. 16).

A lógica de globalizar traz consigo a ideia de tornar igual, de nivelar e de dar as mesmas oportunidades. Nesse processo, as cidades sofrem a homogeneização do singular e estimulam o comportamento por cópia. Sendo assim, ausenta-se a busca pelo novo, por descobrir naquele mesmo espaço o diferente que transforma.

Longe de ser apenas um espaço para execução de uma vida automática, as cidades são artefatos que servem de espaço para a reunião de pessoas e suas individualidades. São pontos de encontros coletivos que contribuem para a construção de uma subjetividade, que ao mesmo tempo impacta na dinâmica dessas cidades, como num processo circular que alimenta ao mesmo tempo em que consome.

Essa dinâmica favorece a mudança coletiva, seja ela paisagística ou, ainda, comportamental. A mudança paisagística por que passa naturalmente uma cidade faz, às vezes, que histórias e experiências sejam transformadas em relatos saudosistas de pessoas que presenciaram uma cidade muitas vezes não conhecida por seus descendentes.

Mas por outro ponto de vista, também é de se perceber que as alterações da imagética da urbe, fazem parte do processo de transformação da mesma, ou seja, da sua própria história, dos almejos civis, governamentais e políticos que conduzem esta memória coletiva (AMARANTE, 2012, p. 55).

Sendo assim, poderíamos nos perguntar: como estamos percebendo essas mudanças? Uma manifestação que vem tentando marcar essa percepção é o graffiti urbano com suas produções permeadas de subjetividade e geradoras de múltiplas percepções. 
v. $8(2)$

$137-155$

mai/ago 2018
Tais práticas de letramento estão voltadas para a concretude da vida dos ativistas, relacionando-se às questões culturais e políticas e visando, de alguma maneira, ampliar suas possibilidades de inserção em um lugar de crítica, contestação e de subversão, no qual, como sujeitos de direitos e produtores de conhecimentos, possam forjar espaços e atuar dentro e fora da comunidade em que vivem. Inserir-se nesses lugares provoca a inscrição em uma complexa rede de relações sociais, na qual, por meio dos discursos, negociam-se a ocupação e a sustentação de formas de participação social compromissadas com as transformações das relações sociais e raciais (SOUZA, 2011, p. 17).

Esse dizer da autora aproxima, a nosso ver, a ideia de graffiti como prática social da concepção de texto que defendemos neste espaço, uma vez que o dinamismo presente na definição de texto como evento se coaduna, justamente, com o entendimento do fazer graffiti como um processo de inscrição em uma complexa rede de relacionamentos.

\section{A relação das pessoas com as obras espalhadas pelos muros da cidade}

Se considerarmos a linguagem como uma "prática social constitutiva de significação e interligada a outras práticas sociais" (BRENT, 2009, p. 119), o discurso pode ser visto como um aspecto semiótico peculiar em relação dialógica com outros aspectos semióticos. É por meio dos discursos que os sujeitos se comunicam, semioticamente, com a realidade e com os outros.

Desta maneira, no ambiente criativo do graffiti, por exemplo, as condições sociais percebidas pelos grafiteiros é que constituem, algumas vezes, o tema de suas criações e, ao executar esses temas, eles nos expõem a um complexo processo de (re)elaboração criativa da realidade. Blikstein (2003, p. 17), ao dizer que "[...] os significados já vão sendo desenhados na própria percepção/cognição da realidade.", já atestava essa atividade interativa tratando justamente desse diálogo permanente entre a significação e a fabricação do real.

Nesta linha, Rink (2013, p. 17) nos apresenta alguns questionamentos que podem nortear a prática e a relação do graffiti e dos grafiteiros com a realidade, "O que querem eles? Enfeitar a cidade, chamar a atenção, estar presente ou contestar o que está posto?". Os depoimentos, as evidências nos muros e a presença cada vez maior nos espaços culturais das cidades nos apontam que o contato com essas produções nos estimulam uma construção fecunda de sentidos e, por sua vez, favorecem a construção da realidade. 
Pois com o conteúdo imagético de seus graffitis, eles favorecem a produção de subjetividade, o que significa também a produção de uma nova forma de produzir cultura, engendrando novos elementos que enriquecem e transformam o imaginário social (RINK, 2013, p. 21).

Assim, as experiências vão sendo reorganizadas pelos sujeitos grafiteiros e, materializadas em arte graffiti, tais experiências passam a ser vividas por outras pessoas, que, impregnadas de seus contextos singulares, (re)significam a obra exibida da maneira mais variada, indicando-nos que a percepção depende de uma construção e de uma prática social.

\section{Aspectos metodológicos}

Nesta seção, abordamos, de forma breve, algumas decisões metodológicas que julgamos adequadas ao cumprimento do propósito deste trabalho. Marcuschi (2010, p. 130), ao falar sobre os aspectos da questão metodológica, deixa claro que um bom problema se constitui de várias formas, por exemplo, "no formato de uma hipótese, de uma observação privilegiada ou de alguma asserção a ser comprovada".

Em nosso caso, podemos dizer que o problema-objeto sobre o qual lançamos nosso olhar adveio da observação da realidade, uma vez que a prática de produção textual que nos forneceu os dados a serem analisados emergiu de uma situação contextual de produção de enunciados e sentidos no universo do graffiti. Em outras palavras, o caso do apagamento e da reconstrução de um graffiti, em Londres, que foi noticiado mundialmente, nos chamou a atenção e se configurou para nós como objeto de estudo pelo fato de apresentar o fenômeno de retomada de objetos discursivos de forma que constituía não somente a materialidade textual, mas, também, o próprio real.

Este estudo, por se configurar em uma reflexão acerca de um processo de construção de sentidos e de reconstrução do real, tem caráter qualitativo, uma vez que, em acordo com o que explica Suassuna (2008, p. 349), "a análise ocorre paralelamente à observação, na medida em que o pesquisador seleciona aspectos que devem ser explorados e decide quais os que devem ser abandonados". Nesse sentido, decidimos pelo método observacional de análise, uma vez que, segundo Gil (2008), nesse tipo de pesquisa observa-se algo que acontece ou já aconteceu. Esse método, a nosso ver, oferece vantagem para esse estudo por, conforme afirma Günther (2006, p. 202), adequar-se ao objeto de estudo; o que dá a nossa análise um caráter mais livre, já que estamos lidando com subjetividades. 
v. 8 (2)

$137-155$ mai/ago 2018

A mostra que selecionamos para comentar neste artigo surgiu em função de esse graffiti ser emblemático, uma vez que, no próprio processo de fazer, flagra-se o fenômeno que a nosso ver pode-se considerar como um caso de metagrafitagem. Ao mesmo tempo em que faz uma crítica, este graffiti é uma reflexão sobre o processo de produção bem como sobre a efemeridade desses materiais textuais.

\section{A recategorização no processo de construção de objetos de discursos: quando grafitar é transformar a realidade}

Alguns depoimentos a respeito do ato de grafitar nos apontam o que Hanks (2008, p. 101) já havia dito ao afirmar que "a produção e a recepção textual podem mudar a realidade social ao alterar os entendimentos e as relações". Uma mostra do que este autor menciona para explicar a potencialidade do texto pode ser lida no relato de Diógenes (2008 apud MAIA, 2008, online): "a valorização dos patrimônios históricos e a busca pela metropolização fizeram com que a cidade fosse percebida como obra de arte".

A partir dessa premissa, nos dedicaremos, a seguir, a analisar uma obra que nos chamou a atenção por sua peculiaridade em termos de produção e por se apresentar como o resultado dos conhecimentos de mundo em correlação com as intenções e as provocações vividas no social.

Através das observações que faremos desta obra específica, buscaremos ainda mostrar o poder de transformação social, cognitiva e estética que os graffitis podem operar na realidade. Para melhor dizer sobre a conexão dos graffitis com o meio e a reconstrução do real operada por eles, começamos delineando algumas observações peculiares a essas obras.

Por não serem aceitas em todos os setores da sociedade, como já adiantamos no início da pesquisa, algumas pessoas, instituições e representações sociais as consideram como ato de marginalidade e, por essa razão, são passíveis de uma existência curta. Para grafiteiros como Leandro Alves (online, 2008), a intervenção urbana ainda é marginalizada: "Acho que somente $20 \%$ da sociedade entendem as mensagens. Os $80 \%$ restantes veem como arte marginalizada. As pessoas não têm acesso, não compreendem a informação que não é maquiada".

Outro fato que pode reduzir o tempo de existência de um graffiti é a luta entre grupos de grafiteiros ou crews. Estes grupos disputam 
espaço e fama e, assim, uma obra pode ser suplantada por outra ou simplesmente alterada à revelia do grafiteiro. Ainda há a questão do respeito; como se fosse um código de conduta, os grafiteiros mais jovens respeitam os que são mais antigos e estes podem, livremente, grafitar por cima do trabalho de um artista mais jovem.

Dentro do contexto que descrevemos aqui, o material que escolhemos para analisar é uma produção que, como qualquer outro graffiti, sofreu a ameaça de ser apagado, mas, no caso deste exemplar, a prefeitura da cidade onde foi produzido é quem promoveu a sua remoção. Um dos jornais que publicou matérias sobre o caso, dizia:

A obra removida de DS estava em uma parede de Essex Road, em Islington, Londres, e se chama "Bad Kitty", uma versão sadomasoquista do personagem Hello Kitty. A pintura, feita com a técnica do stencil, espécie de molde usado para aplicação de tinta, era a sua segunda peça sobre o tema e havia sido pintada na parede em maio deste ano. Agora, ela existe apenas em tela vendida pelo artista em seu site "DS Art" (THE TELEGRAPH, online, 2013).

Como sinalizamos antes, os grafiteiros, em seu cotidiano, estão acostumados com a remoção das peças que produzem. Além das razões que apresentamos anteriormente, há ainda outras, que podem ser: preconceito, vandalismo, ou, até mesmo, por serem consideradas como contravenção. Desta vez, o grafiteiro estava presente no momento em que a obra estava sendo removida e segundo ele,

Ter uma peça ou um graffiti removido nunca me incomodou, é parte do jogo, mas desta vez foi diferente porque durou apenas oito horas. Então, dá pra imaginar como eu fiquei frustrado quando voltei lá e encontrei o cara começando o processo de apagar minha imagem do muro - processo que eu documentei (THE TELEGRAPH, online, 2013).

A seguir, DS pensou que poderia fazer diferente de apenas seguir em frente com outros trabalhos em outros espaços e apostou em uma mensagem que poderia ser deixada como reflexão e como sinal de seu posicionamento enquanto grafiteiro. Assim, pensou: "[...] a foto de um homem removendo a pintura foi uma clara inspiração para a próxima obra naquele local" (DS, 2013, online). 
v. 8 (2)

$137-155$

mai/ago 2018

Figura 1 - Antes e depois da remoção do graffiti
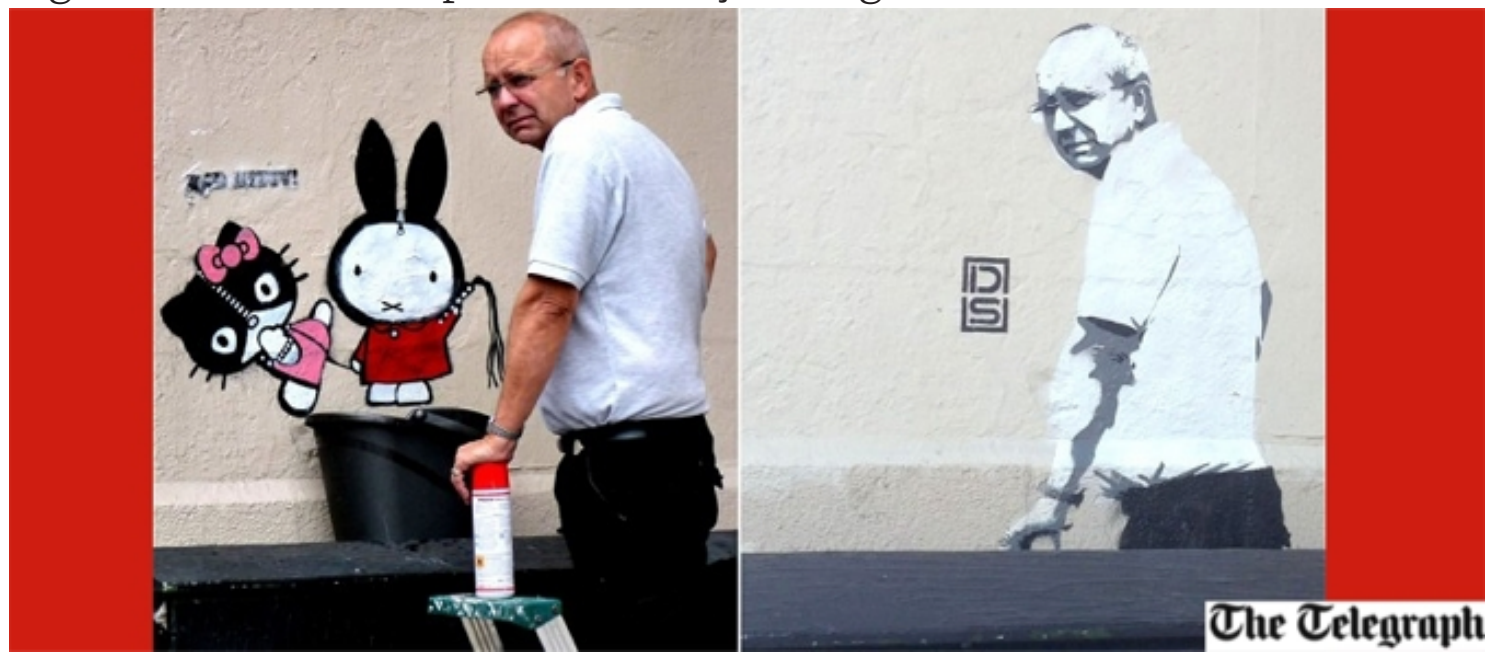

Fonte: The telegraph.

Ele sabia que teria seu graffiti apagado, mas perceber essa ação de modo distinto foi o que marcou a produção que escolhemos para a análise que ora apresentamos. Reagir com um graffiti que retrata e faz refletir sobre a realidade enfrentada pelos artistas e suas peças foi uma maneira que DS encontrou de reescrever essa história.

Para DS, o normal seria deixar as coisas como estão - apagadas - e partir pra outra, mas o momento para os artistas urbanos anda meio esquisito e ele quis deixar isso marcado. - Seria bom deixar o graffiti seguir seu próprio curso, mesmo que isso signifique que grandes obras de arte acabem sendo apagadas, mas é uma época estranha para a arte de rua (THE TELEGRAPH, online, 2013).

Transformar o funcionário encarregado de remover seu trabalho em objeto de discurso, ou seja, em um graffiti, foi a forma de expressão que o grafiteiro encontrou para "vazar" seu discurso para o mundo e fomentar discussões a partir das várias percepções engendradas por todos aqueles que tivessem contato com a obra. Como se pôde ver, a perturbação de DS - usando as palavras de Maturana (2001) - , nesse caso, foi o fato de ter o seu graffiti apagado em tão pouco tempo de existência, ou seja, um elemento externo à materialidade textual foi o responsável pela recategorização da produção em apreço.

Com base na abordagem sobre recategorização que fazemos aqui, arriscamos dizer que ele promove a reconstrução do referente "apagador de graffitis" ao transformá-lo em um graffiti. Desse modo, acreditamos que o artista de rua utiliza esse processo para apresentar seu juízo de valor sobre o referente em questão e instigar outros artistas 
a fazerem o mesmo bem como a população a pensar sobre a política de apagamento da prefeitura local. De acordo com DS (online, 2014), "Banksy [o artista de rua mais famoso da Inglaterra] faz qualquer coisa e é protegido pela prefeitura, mas se qualquer outro artista tão talentoso quanto ele faz alguma coisa, ele é apagado".

Sobre a faculdade individual de perceber e denotar isso por meio da linguagem, Custódio Filho (2011) explica que os usos linguísticos revelam não a realidade, mas uma percepção que se tenha do real. Acreditamos que tenha sido mais ou menos isso que ocorreu nesse caso em apreço, ou seja, a experiência que o sujeito grafiteiro teve no real sofreu elaborações e reelaborações e, por meio da linguagem recorrendo a sprays e estênceis - o artista expressou sua leitura crítica da situação.

Tudo o que apresentamos até aqui sobre os graffitis, sua produção e sobre o modo de trabalhar dos artistas de rua como também a relação destes com a realidade, nos autoriza a dizer que, ao que parece, a todo instante, os grafiteiros vivenciam o processo a que Custódio Filho (2011) se refere, ou seja, a reelaboração dos fatos e do real.

Sob o escopo do conceito dinâmico de texto, dizemos que, recorrendo a uma subjetividade que parece ser inerente ao processo de grafitar, os artistas fazem sua leitura da realidade e nos apresentam o resultado dessa leitura por meio de seus grafismos. Ainda nessa linha de raciocínio, o trabalho interpretativo que se espera para essas produções também faz parte dessa cadeia produtiva de sentidos. É nesse viés que encaixamos a emergência de sentidos produzidos no processo de grafitagem e que não se restringe ao ato de enunciar, pois se recategoriza transformando o que dele [do processo] e com ele [processo] surge.

Zavam (2007, p. 124) afirma, baseando-se em uma visão sociointeracionista de linguagem, que "as categorias e os objetos-dediscurso não são entidades pré-existentes, mas são, antes de tudo, (re)construções dos sujeitos no curso de suas interações verbais" e, por que não dizer, paraverbais também. Na esteira desse pensamento, podemos encaixar a reflexão de Blikstein (2003, p. 46), para quem "a realidade se transforma em referente, por meio da percepçãp/cognição" - de acordo com Greimas - "ou da interpretação humana", como prefere Coseriu". Assim, Blikstein (2003) também nos faz refletir acerca do propósito da reelaboração linguageira e da realidade e nos convida a enxergar as subjetividades existentes nos processos de uso da linguagem. 
v. $8(2)$

$137-155$

mai/ago 2018

Desse modo é que podemos tentar explicar como DS, estando de posse de seu talento, de sua leitura de vida e das histórias acumuladas ao longo de anos de pintura em muros, teve a "presença de espírito" de recategorizar a situação presenciada, ou seja, sua frustração, em um novo trabalho.

Se pensarmos nas produções textuais tradicionais, veremos que qualquer objeto de discurso, uma vez que tenha sido introduzido, precisará ser recategorizado como forma de manter a continuidade discursiva. Levando em conta que consideramos, nesta pesquisa, que texto é um fenômeno social de linguagem, entendemos que a mesma ação de reelaboração empregada na escrita, na fala e nos gestos está ocorrendo com toda sua força nos textos dos artistas de rua e, mais especificamente, neste caso que analisamos.

Desse modo, fica claro para nós que a recategorização demanda, também, a ativação de elementos inferidos do plano contextual e não apenas a localização de uma expressão a partir das menções materializadas. Como mostramos em Oliveira (2012), a reconstrução dos objetos de discurso se dá pela recategorização e ocorre tanto do lado de quem produz o texto, quanto no de quem o recebe.

Trazendo a mesma inquietação para o caso do Graffiti "Bad Kitty", temos a situação de produção inicial, a remoção e a situação de produção final; esse processo, para nós, delineia de modo explícito a questão da reconstrução do real a partir da atitude do grafiteiro que transforma, imediatamente, em graffiti, a situação presenciada. Somos da crença que esse fazer comprova, conforme Zavam (2007, p. 135) explica, que "a reconstrução dos objetos de discurso [...] muitas vezes excede os limites semântico-lexicais".

\section{Considerações Finais}

No decorrer dessa exposição, tecemos algumas reflexões em linhas mais gerais a respeito da produção de graffitis e com mais detalhes sobre a reconstrução do real operada pela produção desses materiais textuais. Ao fim das reflexões, sugerimos que, ao mesmo tempo em que defendemos um estatuto dinâmico de texto para os graffitis, acreditamos ainda que esse tipo de produção textual recategoriza-se para além da materialidade textual, ou seja, a produção de sentidos ocorre para além dos muros.

Para artistas como Haring5 (2013, online), era inconcebível pensar a arte em separado da vida real. Estudar mais detidamente uma

${ }^{5}$ Keith Haring foi um artista gráfico e ativista estadunidense. Seu trabalho reflete a cultura nova-iorquina dos anos 1980. Disponível em: <https://pt.wikipedia.org/wiki/ Keith_Haring>. 
situação de produção textual, como essa que trouxemos aqui nos fez ver mais uma vez como se processa a discretização do mundo nos discursos e como se dá a junção da vida com a arte, do modo como considera Haring.

Tomar o exemplar desta análise do modo como o fizemos nos auxiliou a pensar atentamente acerca dessa característica de dinamismo sobre a qual viemos falando no decorrer da demonstração teórica que empreendemos anteriormente à análise.

Esperamos que as reflexões que oferecemos neste artigo possam, de alguma forma, contribuir para o entendimento da arte do graffiti como parte da vivência cotidiana, como forma de comunicação, de resgate ou até mesmo renovação da paisagem urbana, ou, ao menos, que sirva para despertar a curiosidade ou o respeito por essa manifestação artística.

Cremos que uma pequena contribuição mais imediata dessa abordagem está no fato de o texto - neste caso, principalmente, o graffiti - não ser visto apenas como um conjunto de elementos semióticos, mas antes como um instrumento e um modo de ação social, conforme preconiza Hanks (2008), uma vez que a produção de discursos e de sentidos no contexto da arte urbana nos provou que tais atividades são antes de tudo eventos comunicativos.

\section{Referências}

AMARANTE, Bruno. A imagem fragmento e a fragmentação da imagem. In: DIEL, Maria do Céu (Org.) Linha: escritos sobre a imagem. Campinas: Império do Livro, 2012.

APOTHÉLOZ, Denis; REICHLER-BÉGUELIN, Marie José. Construction de la reference et strategies de designation. In: BERRENDONNER, Alain; REICHLERBEGUELIN, Marie José (Ed.). Du syntagme nominal aux objets-de-discours: SN complexes, nominalizations, anaphores. Suisse: Institut de Linguistic de l'Université de Neuchâtel, 1995. p.273-302.

BEAUGRANDE, Robert de. New foundations for a science of text and discourse: Cognition, communication, and the freedom of access to knowledge and society. Norwood: Ablex, 1997. Disponível em: <http://www.beaugrande.com/ new_foundations_for_a_science.htm>. Acesso em: 15 jun. 2013.

BENTES, Anna Christina; REZENDE, Renato. Texto: conceitos, questões e fronteiras [con]textuais. In: SIGNORINI, Inês. (Org.). [Re]discutindo texto, gênero e discurso. Sao Paulo: Parábola, 2008.

BLIKSTEIN, Izidoro. Kaspar Hauser ou a Fabricação da realidade. 9. ed. São Paulo: Cultrix, 2003.

BRENT, Guilherme Rocha. Análise do discurso: uma proposta transdisciplinar para investigação crítica da linguagem. In: LIMA, Cássia Helena Pereira; 
V. 8 (2)

$137-155$ mai/ago 2018

PIMENTA, Sônia Maria Oliveira; AZAVEDO, Adriana Maria Tenuta. Incursões semióticas: teoria e prática de gramática sistêmico-funcional, multimodalidade, semiótica social e análise crítica do discurso. Rio de Janeiro: Livre Expressão, 2009.

CIULLA, Alena Silva. Os processos de referência e suas funções discursivas: O universo literário dos contos. 2008. 205 f. Tese (Doutorado em Linguística). Programa de Pós-Graduação em Linguística, Universidade Federal do Ceará, Fortaleza, 2008.

COSTA, Maria Helenice Araújo. Ariel e a noção de acessibilidade referencial: ampliando os limites do discurso. In: CAVALCANTE, Mônica Magalhães et al. (Org.). Texto e discurso sob múltiplos olhares: referenciação e outros domínios discursivos. Rio de Janeiro: Lucerna, 2007. p.40-73. v.2.

CUSTÓDIO FILHO, Valdinar. Múltiplos fatores, distintas interações: esmiuçando o caráter heterogêneo da referenciação. 2011. 331f. Tese (Doutorado em Linguística) - Programa de Pós-Graduação em Linguística, Universidade Federal do Ceará, Fortaleza, 2011.

EMOL. Notas de aula. Introdução à arte de rua: a cultura do graffiti como escrita de rua. Porto Iracema das Artes: Fortaleza, 2014.

FURTADO, Janaína Rocha. Inventi (Cidade): os processos de criação no graffiti. 2007. 165 f. Dissertação (Mestrado em Psicologia) - Programa de Pós-Graduação em Psicologia, Universidade Federal de Santa Catarina, 2007.

GIL, Antonio Carlos. Como elaborar projetos de pesquisa. 4. ed. São Paulo: Atlas, 2002. 176 p.

GÜNTHER, Hartmut. Pesquisa Qualitativa Versus Pesquisa Quantitativa: Esta É a Questão? Psicologia: Teoria e Pesquisa, Brasília, v. 22, n. 2, p.201-210, maio-ago, 2006.

HANKS, Willian. Texto e textualidade. In: BENTES, Anna Christina; REZENDE, Renato; MACHADO, Marco Antônio (Org.). Língua como prática social: das relações entre língua, cultura e sociedade a partir de Bourdieu e Bakhtin. São Paulo: Cortez, 2008. p. 118-168.

HOMEM enviado para apagar grafite acaba desenhado no muro. The Telegraph. Londres, 30 julho 2013. Disponível em: <http://www.hiphopweb.org/index. php/noticias/1741-homem-enviado-para-apagar-grafite-acaba-desenhadono-muro>. Acesso em: 08 set. 2014.

JAGUARIBE, Vicência Maria Freitas. Os caprichos e as condescendências do discurso literário. In: CAVALCANTE, Mônica Magalhães et al. (Orgs.). Texto e discurso sob múltiplos olhares: referenciação e outros domínios discursivos. Rio de Janeiro: Lucerna, 2007. p. 221-249. v.2.

KOCH, Ingedore Villaça. Desvendando os segredos do texto. 5. ed. São Paulo: Cortez, 2006.

KOCH, Ingedore Villaça. Introdução à linguística textual: trajetória e grandes temas. 2. ed. São Paulo: Martins Fontes, 2004.

LEITE, Ricardo Lopes. Da Recategorização Metafórica à Metaforização Textual. In: CAVALCANTE, Mônica Magalhães et al. (Org.). Texto e discurso 
sob múltiplos olhares: referenciação e outros domínios discursivos. Rio de Janeiro: Lucerna, 2007. p.104-122. v.2

LIMA, Silvana Maria Calixto. (Re)categorização metafórica e humor: trabalhando a construção dos sentidos. 2003. $171 \mathrm{f}$. Dissertação (Mestrado em Linguística) - Programa de Pós-Graduação em Linguística, Universidade Federal do Ceará, Fortaleza, 2003. Disponível em: <http://www.repositorio. ufc.br/handle/riufc/8752>. Acesso em: 20 nov. 2016.

MAIA, Janine. Fortaleza como obra do grafite. Diário do Nordeste, Fortaleza, 13 de setembro de 2008. Disponível em: <http://diariodonordeste.verdesmares. com.br/cadernos/cidade/fortaleza-como-obra-do-grafite-1.342445>. Acesso em: 10 set. 2014.

MARCUSCHI, Luiz Antônio. Aspectos da questão metodológica na análise da interação verbal: o continuum qualitativo-quantitativo. In: MARCUSCHI, Beth; AGUIAR, Marigia Ana de M. (Org.). Luiz Antonio Marcuschi, seu percurso, seus textos: uma homenagem. 1. ed. Recife: PGLetras, 2010. v. 1. 153 p.

MATURANA, Humberto. Cognição, ciência e vida cotidiana. Organização e tradução de Cristina Magro e Vitor Paredes. Belo Horizonte: UFMG, 2001.

MONDADA Lorenza; DUBOIS, Danielle. Construção dos objetos do discurso e categorização: uma abordagem dos processos de referenciação. In: CAVALCANTE, Mônica Magalhães; RODRIGUES, B. B.; CIULLA, Alena Silva (Org.). Referenciação. São Paulo: Contexto, 2003, p.17-52.

OLIVEIRA, Francisca Poliane Lima de. Da construção à co-construção de referentes: um olhar sobre os mecanismos cognitivo-discursivos subjacentes à produção e à compreensão de peças de divulgação elaboradas por designers. 2012. 170 f. Dissertação (Mestrado em Linguistica Aplicada) - Programa de Pós-Graduação em Linguística Aplicada, Universidade Estadual do Ceará, Fortaleza, 2012.

ORLANDO, José Antônio. A arte do grafite. 2011. Disponível em: <http:// semioticas1.blogspot.com.br/2011/07/arte-do-grafite_15.html>. Acesso em: 25 abr. 2013.

RINK, Anita. Graffiti: intervenção urbana e arte. Curitiba: Appris, 2013.

SANTAELLA, Lúcia. o que é semiótica. São Paulo: Brasiliense, 2003.

SOUZA, Ana Lúcia Silva. Letramentos de reexistência: poesia, grafite, música, dança: Hip-Hop. São Paulo: Parábola Editorial, 2011.

SUASSUNA, Livia. Pesquisa qualitativa em Educação e Linguagem: histórico e validação do paradigma indiciário. Perspectiva, Florianopolis, v. 28, n. 1, p. 341-377, jan-jun. 2008. Disponível em: <http://www.perspectiva.ufsc.br>. Acesso em: 20 abr. 2014.

ZAVAM, Áurea. São axiológicas as anáforas encapsuladoras? In: CAVALCANTE, Mônica et al. (Org.). Texto discurso sob múltiplos olhares: referenciação e outros domínios discursivos. Rio de Janeiro: Lucerna, 2007. p. 221-249. v.2. 